\title{
REFLEXÕES SOBRE DIREITOS HUMANOS E O MULTICULTURALISMO NO BRASIL
}

\section{REFLECTIONS ON HUMAN RIGHTS AND MULTICULTURALISM IN BRAZIL}

\author{
Michel Canuto de Sena* \\ Heitor Romero Marques ${ }^{* \star}$ \\ Ady Faria da Silva \\ Paulo Roberto Haidamus de Oliveira Bastos
}

\begin{abstract}
Resumo: O presente estudo traz uma abordagem atualizada sobre direitos humanos e multiculturalismo no Brasil. Neste contexto, fez-se uma análise dos primeiros países que adotaram, no direito interno, a dignidade da pessoa humana como direito fundamental, pois somente após a segunda guerra mundial a Organização das Nações Unidas, adotou esse direito como princípio fundamental, ou seja, inerente a todos os seres humanos. Ainda, o estudo analisa como são aplicados os direitos humanos no Brasil e o multiculturalismo como parte de uma sociedade globalizada, permeada por violações, sempre buscando mesclar manifestações culturais e movimentos sociais ao direito humano interno. O objetivo deste estudo é revelar a importância dos direitos humanos e a construção de um eficaz multiculturalismo combinado aos direitos humanos no Brasil. Regra geral, este estudo apoiar-se-á nos estudos bibliográficos acerca dos direitos humanos; e no multiculturalismo.
\end{abstract}

Palavras-chave: Direitos humanos. Multiculturalismo. Democracia. Tratados Internacionais.

Abstract: The present study brings an updated approach on the human rights and multiculturalism in Brazil. In this context, we investigated the first countries that have adopted the human dignity as a fundamental right, since only after the World War II

\footnotetext{
* Mestre com linha de pesquisa na Lei n 11.196/05 - financiamento de pesquisas pela Universidade Federal de Mato Grosso do Sul - UFMS. Possui experiência como Professor- Tutor na modalidade EAD pela Universidade Federal de Mato Grosso do Sul - UFMS.

Especialista em Administração Rural pela Universidade Federal de Lavras, mestre em agronegócios pela Universidade Federal de Mato Grosso do Sul. Doutor em Medicina Veterinária Preventiva pela Unesp / Jaboticabal. Professor da Universidade Católica Dom Bosco (UCDB) nos cursos de Medicina Veterinária e Zootecnia.

Advogado atuante nas áreas civil, trabalhista, previdenciário e criminal. Mestrado e Doutorando pela Universidade de Buenos Aires (UBA).

Doutorado em Educação pela Pontifícia Universidade Católica de São Paulo (PUC-SP). Professor Titular Aposentado pela Universidade Federal de Mato Grosso do Sul (UFMS). Professor Permanente, Pesquisador Sênior do Programa de Pós-Graduação Stricto Sensu em Saúde e Desenvolvimento na Região Centro-Oeste (PPGSD).
} 
the United Nations, took the dignity of the humans as a fundamental principle, inherent in all human beings. Moreover, the study reviews how the human rights are applied in Brazil and how the multiculturalism acts as part of a globalized society which is permeated by violations, always trying to merging cultural manifestations and social movements into the human rights. The objective of this study is to show the importance of human rights and the development of an efficient combination of multiculturalism and human rights in Brazil. As a general rule, this study was based on bibliographic documents on human rights; and multiculturalism.

Keywords: Human rights. Multiculturalism. Democracy. International Treaties. 


\section{INTRODUÇÃO}

A expressão direitos humanos tornou-se muito falada e pouco compreendida, isso ocorre devido ao tratamento, definição e abordagem. Tendo em vista que os direitos humanos nascem de um processo histórico de luta pela dignidade das pessoas, do clamor social por respeito e reconhecimento.

Segundo a Organização das Nações Unidas (ONU) os Direitos humanos são direitos inerentes a todos os seres humanos, independentemente de raça, sexo, nacionalidade, etnia, idioma, religião ou qualquer outra condição, e nos termos da Declaração Universal "Todos os homens nascem livres e iguais em dignidade e direitos". Desse modo, a liberdade e igualdade dos homens não é apenas um fato, mas sim um valor merecido e de igual teor a todos.

A partir de então o presente estudo retrata os direitos humanos internacional, após a Revolução Americana e Francesa instituir que toda pessoa tem o direito de ser reconhecida enquanto ser humano. Ainda, os princípios de liberdade, igualdade e fraternidade, instituído pela Revolução Francesa, ganharam força e foram proclamados como direitos do homem. Assim, tais direitos passaram a ser considerados como inalienáveis, e somente leis eleitas democraticamente podem restringir limitações ou restrições ao exercício desses direitos.

No Brasil os direitos humanos possui trajetória marcada por diferentes movimentos políticos, econômicos, sociais, culturais, internos e externos, advindos com a redemocratização brasileira. Todavia, com a Constituição Federal brasileira de 1988, escrita com a partição popular foi instituído a proteção aos direitos humanos como princípio fundamental que busca eliminar todos os tipos de desigualdades, tendo em vista que o Brasil é um país de multiculturas, com diferentes crenças, raças, religiões dentre outros.

Dessa maneira o presente estudo analisa os direitos humanos na perspectiva internacional, e a proteção dos direitos humanos interno, no Brasil tendo em vista o multiculturalismo nacional. 


\section{METODOLOGIA}

O presente estudo utilizou a revisão narrativa e compreensiva de estudos e pesquisas sobre direitos humanos e o multiculturalismo no Brasil. As referências apresentadas pela literatura sobre o direito humanos e multiculturalismo, foram coletadas a partir das bases de dados Medline, SciELO e Lilacs.

A busca limitou-se aos estudos de corte transversal, publicados no período compreendido entre 2012 e 2017, nos idiomas português, inglês e espanhol. Foram analisados, ainda, estudos que investigam as ações necessárias sobre os direitos humanos e multiculturalismo no Brasil. Os descritores utilizados na busca da revisão foram: "direitos humanos", "multiculturalismo", nos idiomas português, espanhol e inglês. Como resultado dessa estratégia de busca, encontrou-se total de 3.250 artigos nas bases selecionadas. Estabeleceram-se, os seguintes critérios de seleção de artigos: 1) identificar a prevalência dos direitos humanos internacional; 2) identificar os fatores associados ao multiculturalismo no Brasil; e 3) ter um desenho transversal.

Os resumos foram analisados e os artigos com texto completo que preencheram todos os critérios de inclusão sobre o tema proposto. Outras onze referências, embora não estivessem relacionadas diretamente à prevalência ou fatores associados aos direitos humanos e multiculturalismo, foram incluídas nesta revisão, em função de trazerem informações importantes ao tema, tais como finalidades, conceitos, estatísticas, normas e legislações específicas.

\section{DIREITOS HUMANOS NA CIÊNCIA POLÍTICA: PERSPECTIVA HISTÓRICA INTERNACIONAL}

Os direitos humanos possuem raízes nas civilizações e religiões do mundo. Deste modo, as fontes normativas dos direitos humanos remontam à antiguidade, buscando mapear um curso moral para as atividades humanas. Tais concepções posteriormente foram formalizadas como Leis Naturais, pressupondo a existência e legitimidade de princípios e valores universais, buscando construir uma ordem social baseada no direito, em que as pessoas seriam livres e os Estados representariam e 
protegeriam os interesses de seus cidadãos, abriu-se para o campo político no século XVIII, após as Revoluções Americana e Francesa (ANTAS JUNIOR, 2005).

Baseavam-se no princípio de que toda pessoa tem o direito de ser reconhecida enquanto ser humano. Com a Revolução Francesa em particular, os princípios de liberdade, igualdade e fraternidade ganharam força e foram proclamados como direitos do homem, ambos os documentos apresentam diversas semelhanças, declarando os direitos como inalienáveis, afirmando que limitações e restrições ao seu exercício devem ser introduzidas por meio das leis elaboradas por entidades democraticamente eleitas, além de protegerem direitos similares, como liberdades, segurança das pessoas, entre outros aspectos (MUNIZ, 2009).

Desse modo, na declaração francesa, direitos humanos são interpretados como uma forma de política comprometida com um senso moral de história para vencer a dominação, a opressão e o sofrimento. No entanto, na norte-americana o livre-arbítrio conduziria à promoção dos direitos humanos ajustando às demandas morais as realidades empíricas (ANTAS JUNIOR, 2005).

Por isso, as declarações, francesas e americanas possuíam a essência moral e político que se fundamentava em seus ordenamentos jurídicos nacionais, tendo em vista que nenhuma ênfase ao tema era dada no âmbito do direito internacional. Somente a partir de 1945, que o tema sobre direitos humanos conquistou destaque internacional como um elemento-chave para a ordem mundial (MUNIZ, 2009).

Os direitos humanos converteram-se em ferramenta política durante o período da guerra fria invadindo a política externa, tornando sua desnacionalização poderosa arma de política totalitária, que permitiu a imposição de normas e valores de governos perseguidores aos seus oponentes, incapacitando os Estados-nações europeus de garantir os direitos humanos àqueles que perderam seus direitos nacionalmente garantidos (ARENDT, 2007).

Assim, somente após a Segunda Guerra Mundial, com divulgações das atrocidades do Holocausto, onde vitimas perderam seus direitos, e o termo direitos humanos tornou-se idealismo sem esperança, fez surgir à internacionalização para 
prevenção de guerra e proteção aos direitos humanos foi estabelecida (AMARAL; BORANGA, 2015).

A Organização das Nações Unidas (ONU) foi responsável pelo primeiro documento formal de âmbito internacional versando sobre os direitos humanos, com a Declaração Universal dos Direitos Humanos (UDHR). Todavia essa declaração não possuía poder de coerção e teve que contar com comprometimento dos estados signatários para evitar práticas e políticas internas contraditório com os princípios por ela defendidos, somente tempos depois ela passou a ter validade legal no âmbito internacional (MUNIZ, 2009).

A transição dos direitos naturais para os direitos humanos teve como base a substituição filosófica e de suas origens institucionais. A condição mais elevada dos direitos humanos é vista como o resultado da sua universalização jurídica, no entanto a universalidade empírica não deve ser entendida como princípio normativo.

No entanto, têm-se alguns pensadores contrários aos direitos humanos dentre eles Burke que considerava a declaração francesa insípida, e natural o respeito ao rei e temor a Deus (BURKE, 1982). O poder do livre-arbítrio de moldar o mundo de acordo com suas preferências foi obscurecido pela ilimitada força do Estado de moldar os indivíduos de acordo com seus interesses. Logo, a sociedade passou a não ser mais vista como o produto da ação individual deliberada, entretanto a pessoa tornou-se produto da estrutura social, politicamente e cognitivamente mais importante. Nesse sentido Max (2010, p.48) questionava:

Quem é esse homme que é diferenciado do citoyen: ninguém mais ninguém menos que o membro da sociedade burguesa. Por que o membro da sociedade burguesa é chamado de "homem", pura e simplesmente, e por que os seus direitos são chamados de direitos humanos? A partir de que explicaremos esse fato? A partir da relação entre o Estado político e a sociedade burguesa, a partir da essência da emancipação política. Antes de tudo, constatemos o fato de que os assim chamados direitos humanos, os droits de l'homme, diferentemente dos droits du citoyen, nada mais são do que os direitos do membro da sociedade burguesa, isto é, do homem egoísta, do homem separada do homem e da comunidade. 
Marx distingue homme e citoyen, para ele o citoyen é o homem que goza formalmente da igualdade política, mas vive materialmente na desigualdade econômica, ou seja, membro da sociedade política como todo; o homme é o burguês que consegue de fato a liberdade porque possui, além dos direitos formais, os direitos substanciais com o poder econômico, são emancipadores reais de si próprios. Nessa reflexão, ele procura mostrar que o cidadão livre, igual, fraterno, proprietário não passa de espectro, de uma abstração (MARX, 2010).

Para Marx e Engels, se por um lado os direitos humanos vão além dos velhos vínculos políticos, por outro, eles expressam o antagonismo de uma universalidade marcadamente abstrata no sentido ideológico-idealista: eles são "vagos" o suficiente para que todos possam identificar-se com eles e, paralelamente, resguardar interesses de classes e culturas específicas em detrimentos das demais, mascarando dominados e oprimidos até de si mesmos (TOSI; FRAGOSO, 2017).

$\mathrm{Na}$ obra Homo Sacer, Agamben trata de explorar as zonas cinzentas, difusas, que foram indicadas por Hannah Arendt em A Condição Humana, (ARENDT, 2007, p. 299). Argumenta Agamben (2002, p. 132) que:

No sistema do Estado-nação, os ditos direitos sagrados e inalienáveis do homem mostram-se desprovidos de qualquer tutela e de qualquer realidade no mesmo instante em que não seja possível configurá-los como direitos dos cidadãos de um Estado. Isto está implícito, se refletimos bem, na ambiguidade do próprio título da declaração de 1789: Déclaration des droits de l'homme et du citoyen, onde não está claro se os dois termos denominam duas realidades autônomas ou formam em vez disso um sistema unitário, no qual o primeiro já está desde o início contido e oculto no segundo; e, neste caso, que tipo de relações existe entre eles. (AGAMBEN, 2002, p. 132).

Nesse sentido, para Agamben e Marx os direitos humanos são meramente direitos burgueses e a declaração dos direitos humanos é a passagem da soberania divina para soberania nacional. Agamben (2002, p.135) assegura que:

As declarações dos direitos devem então ser vistas como o local em que se efetua a passagem da soberania régia de origem divina à soberania nacional. Elas asseguram a exceptio da vida na nova ordem estatal que deverá suceder à derrocada do ancien régime. 
Que, através delas, o "súdito" se transforme, como foi observado, em "cidadão", significa que o nascimento - isto é, a vida nua natural como tal - torna-se aqui pela primeira vez [...] o portador imediato da soberania. (AGAMBEN, 2002, p. 132).

Nas palavras de Agamben o principio da natividade e da soberania se fundiram formando um novo estado, e o homem livre, igual, dotado de espírito crítico e politizado não é fundamento nem sustentação para soberania nacional, onde as condições que sustentam a cidadania começam a romper-se. Sem cidadania, o humano, sujeito de direitos inalienáveis e imprescritíveis, está perdido, pois a mera humanidade do individuo não é suficiente para fazer dele sujeito de direitos. A sociedade burguesa lança os fundamentos para o Estado democrático de direito como estado de exceção (TOSI; FRAGOSO; 2017).

Por outro viés Bobbio expõe as duas criticas recorrentes e opostas a declaração: a de "excessiva abstratividade pelos reacionários e conservadores em geral; e de excessiva ligação com os interesses de uma classe particular, por Marx e pela esquerda em geral" (BOBBIO, 2004, p. 45). Em analise as criticas conservadoras Bobbio (2004, p. 45):

A acusação de abstratividade foi repetida infinitas vezes: de resto, a abstratividade do pensamento iluminista é um dos motivos clássicos de todas as correntes antiiluministas. Não preciso repetir a célebre afirmação de De Maistre, que dizia ver ingleses, alemães, franceses e, graças a Montesquieu, saber também que existiam os persas, mas o homem, o homem em geral, esse ele nunca vira e, se é que existia, ele o ignorava. Mas basta citar - menos conhecido, mas não menos drástico - um juízo de Taine, segundo o qual a maior parte dos artigos da Declaração "não são mais do que dogmas abstratos, definições metafísicas, axiomas mais ou menos literários, ou seja, mais ou menos falsos, ora vagos, ora contraditórios, suscetíveis de mais de um significado e de significados opostos [...], uma espécie de insígnia pomposa, inútil e pesada, que [...] corre o risco de cair na cabeça dos transeuntes, já que todo dia é sacudida por mãos violentas". (BOBBIO, 2004, p. 45).

Por outro lado, na sequência de argumentação, Bobbio (2004, p.46) apresenta a critica de esquerda, afirmando que: 
[...] Declaração, em vez de ser demasiadamente abstrata, era tão concreta e historicamente determinada que, na verdade, não era a defesa do homem em geral, que teria existido sem que o autor das Noites de São Petersburgo o soubesse, mas do burguês, que existia em carne e osso e lutava pela própria emancipação de classe contra a aristocracia, sem se preocupar muito com os direitos do que seria chamado de Quarto Estado - foi feita pelo jovem Marx no artigo sobre A questão judaica,[...]. De nenhum modo se tratava do homem abstrato, universal! O homem de que falava a Declaração era, na verdade, o burguês; os direitos tutelados pela Declaração eram os direitos do burguês, do homem (explicava Marx) egoísta, do homem separado dos outros homens e da comunidade, do homem enquanto mônada isolada e fechada em si mesma. (BOBBIO, 2004, p. 46).

No que tange as essas criticas, os direitos humanos são ao mesmo tempo abstratos e concretos, Bobbio afirma que a força dos direitos humanos está justamente no seu caráter abstrato, que reconhecem diversos sujeitos sociais em diferentes épocas com expressões de lutas e conflitos sociais.

Desse modo, o movimento histórico dos direitos humanos na modernidade se dividem em três fases: (I) fase universal, mas não positiva; (II) fase positiva, mas não universal; e (III) fase universal e positiva.

Nesse diapasão, a primeira fase trata da teoria jusnaturalista, em que é afirmada a excelência de direitos universais, porém, esses direitos ainda não são positivados, senão em partes. Trata-se de grande época do jusnaturalismo moderno, iniciada com o renascimento até o iluminismo, tendo como protagonista Hobbes, Espinosa, Locke, Rousseau e Immanuel Kant, época que se conclui com a crítica de Hegel (BOBBIO, 2004). Na segunda fase encontram-se as declarações decorrentes das revoluções burguesas, influenciadas pelos filósofos e jusnaturalistas que influenciaram os tratados políticos-filosóficos de outros autores do mesmo período. De todas essas revoluções, surgem as primeiras declarações (Bill of rights).

Já a terceira fase tem inicio com a declaração universal dos direitos humanos da ONU de 1948, transformando os direitos humanos em universais e positivos, pois a mesma assinada por todos os países, diferentemente das declarações iniciais que eram restritas as suas fronteiras (BOBBIO, 2004).

Em síntese, os direitos humanos podem ser indeterminados, incertos, contraditório, com diferenças e desigualdade como alguns críticos afirmam, mas 
apesar dessas criticas os direitos humanos continuam sendo as vozes que clamam por justiça e podem ser representados: como uma meta narrativa; semântica da sociedade moderna; instituição social; categoria jurídica; um conceito; um discurso; uma ideologia; uma retórica; um ideal; como um conjunto de critérios morais instituídos dentro do sistema jurídico (MONTERO, 2012).

\section{DIREITOS HUMANOS NO BRASIL}

Apesar das diferenças internacionais marcantes na ideologia, níveis e estilos de desenvolvimento econômico com padrões de evolução política, fizeram os estados adotar nos discursos, as normas de direitos humanos enunciados na Declaração Universal dos Direitos Humanos e nos Pactos Internacionais de Direitos Humanos. Este consenso apresenta forte caso prima facie para o universalismo relativamente, isto é, para um fraco relativismo cultural (DONNELLY, 2003).

Os direitos humanos no Brasil foram constituídos sob a égide da ditadura militar, tendo como marca a luta contra o regime autoritário e suas frequentes violações às garantias fundamentais, somente no retorno ao regime democrático que os direitos humanos se tornaram causa de Estado (ENGELMANN; MADEIRA, 2015).

Assim, a colonização pelos portugueses e o período da ditadura militar trouxeram diversas consequências que marcaram as relações de desigualdades econômica e social até os dias atuais com reivindicações populares. Somente em meados dos anos oitenta, começa ficar claro o desenvolvimento econômico, social e a transição para democracia. O governo brasileiro passa a reconhecer a obrigação do estado de proteger e promover os direitos humanos através do Programa Nacional dos Direitos Humanos (PNDH-1).

Os direitos humanos não são porém, apenas um conjunto de princípios morais que devem informar a organização da sociedade e a criação do direito. Enumerados em diversos tratados internacionais e constituições, asseguram direitos a indivíduos e coletividades e estabelecem obrigações jurídicas concretas aos Estados. Compõemse de uma série de normas jurídicas claras e precisas, destinadas a proteger os interesses mais fundamentais da pessoa humana. São 
normas cogentes ou programáticas, que obrigam os Estados nos planos interno e externo.

O Programa Nacional dos Direitos Humanos fortaleceu a mudança na concepção de direitos humanos, tendo em vista que foi a primeira vez que o governo brasileiro adotou essa política estabelecendo que os direitos humanos devem ser visto como direito para todos, nacionais ou não. O Programa atingiu um dos seus objetivos com "um marco referencial para as ações governamentais e para a construção, por toda a sociedade, da convivência sem violência que a democracia exige". (BRASIL, 2010, p. 189).

O programa nacional de direitos humanos reconhece o papel e a obrigação do Estado como órgão promotor dos direitos humanos, bem como a universalidade e indivisibilidade de tais direitos. A adoção de conceito largo de direitos humanos, que engloba direitos civis e políticos, mas, também, econômicos, sociais e culturais, pelo governo brasileiro reforça perspectivas defendidas por organismos internacionais. (PINHEIRO; MESQUITA NETO, 1997).

Em suma, o Programa exprime plena consciência de que, para conter a violência, estrutural da pobreza, da fome e do desemprego precisa ser enfrentada em termos da ação governamental imediata, motivada por razões de emergência diante de situações claramente epidêmicas (PINHEIRO; MESQUITA NETO, 1997).

A partir de então, para ampliar os direitos humanos, o Brasil ratificou tratados internacionais, abriu suas fronteiras a observadores internacionais e, por vias diplomáticas, passou a participar ativamente em conferências da ONU e em outras instâncias multilaterais de negociação (KOERNER, 2003).

Desse modo, tratados internacionais ratificados pelo Brasil que versam sobre direitos humanos incorporam no ordenamento jurídico, reproduzindo dispositivos dos tratados que versam sobre direitos fundamentais de proteção e promoção dos direitos humanos no foro doméstico, como resultado da atividade do estado social e democrático de direito (KOERNER, 2003). Nesse contexto, o Brasil busca através de políticas efetivar a criação de oportunidades para todos com a interação entre Estado e sociedade civil, compromisso compartilhado através da 
participação social na construção e no monitoramento de políticas publicas para consolidação dos direitos humanos (BRASIL, 2010).

O Brasil e outros países em desenvolvimento, com crescimento econômico, distribuição de renda e justiça social, vêm constituindo elemento fundamental para promoção dos direitos humanos, mantendo o compromisso em proteger os direitos humanos, civis, políticos, econômico, sociais e culturais, buscando reduzir as diferenças entre os mais privilegiados e os mais pobres.

Além disso, o caráter indivisível dos direitos humanos se manifesta na impossibilidade de se dissociar os diversos direitos previstos nos documentos internacionais, regionais e nacionais. A indivisibilidade e a interdependência exigem a conjugação dos direitos civis com os direitos sociais, econômicos e culturais, tendo em vista que a "declaração de 1948 combina o discurso liberal e o discurso social da cidadania, conjugando o valor da liberdade ao valor da igualdade" (PIOVESAN, 2005 , p. 44). Essa ideia de indivisibilidade dos direitos humanos serve como argumento para que os direitos sejam considerados como parte de um único sistema, o que implica em Ihes atribuir igual atenção sem selecionar categorias para concentrar esforços de proteção e garantir sua efetivação.

Todavia, a indivisibilidade dos direitos humanos recebe diversas definições na literatura, mas de maneira geral todas se baseiam na ideia de que todos os direitos fundamentais, independentemente de divisões em gerações ou grupos específicos, fazem parte de um sistema de normas, as quais possuem uma relação especial de dependência. Essa relação é qualificada pelo fato de que a efetivação de um direito depende da realização dos demais, de modo que a seleção de apenas alguns perderia o potencial de realização dos direitos humanos (MONTERO, 2012).

\section{MULTICULTURISMO E DIREITOS HUMANOS NO BRASIL}

O multiculturalismo pode ser definido como força integradora e unificadora salientada por Bauman (SOUSA, 2010) como fronteiras culturais, que visa o desenvolvimento humano, justiça social, e possui a diversidade como compositora 
da sociedade definindo a convivência em um país, região ou local de diferentes culturas, tradições, visões de vida e valores (UNESCO, 2002).

Desse modo o multiculturalismo configura-se como política de gestão da multiculturalidade e/ou movimentos culturais demandados pela valorização da diferença como fator de expressão de identidades. Multiculturalismo leva a modificações deste padrão e coloca a diversidade cultural e, consequentemente, a politização da cultura no centro das discussões teóricas sobre direitos humanos (BARATTO, 2014).

No plano das relações internacionais, a defesa normativa da importância da diversidade cultural resultou na modificação da compreensão do conceito de universalidade dos direitos humanos, que passou a serem tolerantes as reivindicações baseadas na diversidade cultural (BARATTO, 2014).

Desse modo, os direitos humanos cada vez menos se limitam às fronteiras nacionais, pois envolve unificação política entre os diferentes países do mundo "(...) não existe mais no mundo atual qualquer possibilidade de evitar a constituição jurídico-moral de uma 'sociedade multicultural', ou de substituí-la por sociedades nacionais ou ideológicas, por tradições de valores herdados" (OLIVEIRA; SOUZA, 2011).

Para muitas reivindicações multiculturais, tais como o direito de autonomia concedido às várias comunidades indígenas nos EUA e no Canadá, questões pertinentes ao casamento, à guarda dos filhos e a redistribuição de direitos sociais não necessariamente precisam seguir os padrões estipulados para os outros cidadãos. Reconhecer que uma comunidade cultural é importante implica aceitar legalmente suas normas de organização social e regulação da vida social de seus indivíduos (SHACHAR, 2001).

No debate dos direitos humanos, essa tensão entre igualdade de todos os indivíduos para o exercício dos direitos humanos e valorização da diversidade cultural é evidenciada pelo embate entre o universalismo versus relativismo cultural. Essas duas posições são antagônicas, mas estritamente interligadas.

Para os universalistas, os direitos humanos estão fundamentados na igualdade de todos os indivíduos, o mesmo pressuposto jurídico-politico do sistema 
de direitos de cidadania que assegura os direitos no plano interno da maioria dos Estados de direito contemporâneos. Esse sistema, que foi expandido pelo DIDH, seria o modelo mais eficaz para garantir as condições mínimas necessárias ao pleno desenvolvimento de cada ser humano. O titular de direitos e o individuo, e, para os universalistas, a aceitação dos instrumentos jurídicos internacionais pelos Estadosnação, ainda que nominal, possibilitaria condições excelentes para a implementação e resguardo dos direitos humanos. As normas de direito positivo do sistema internacional são ou serão suficientes para a eficácia destes.

Para os relativistas, em termos gerais, o fato de o modelo de cidadania ocidental considerar o individuo como sujeito de direitos, resguardado pelas normas positivas laicas do direito oficial, sejam elas nacionais ou internacionais, não confere pronta aceitação desse padrão em todo mundo.

O direito não se resume ao positivado nas normas oficiais; ele também mantém uma relação estreita com os valores culturais dos sujeitos a que se destina. $E$, nesse aspecto, direitos humanos não podem ser universais, dada a diversidade cultural existente no planeta. Os seres humanos são culturalmente diferentes. Para muitas sociedades não ocidentais, por exemplo, não faz sentido falar na proteção do individuo, desconsiderado de sua comunidade. Como bem ilustra o debate asiático dos direitos humanos, existem culturas que priorizam o bem-estar da comunidade frente ao interesse do individuo, como valor fundamental a ser mantido pelo Estado. Para essa posição, se a democracia consiste em um valor importante para as relações internacionais entre estados e povos, então não é possível negar a manutenção de padrões culturais diferentes do ocidental em matéria de direitos humanos.

Desse modo, a política brasileira reside nas diferenças associado ao problema da construção de instituições democráticas e não do Estado nacional. As disputas políticas recentes em torno da diversidade cultural e do respeito às diferenças têm, com efeito, substrato, a defesa e robustecimento do estado democrático de direito. Por essa razão, no debate contemporâneo sobre a democracia os processos de construção de uma Esfera Pública Política tem ganhado um lugar central (MONTERO, 2012). 


\section{CONCLUSÃO}

A Declaração Universal dos Direitos Humanos representa um grande avanço para a humanidade, a partir dela que internacionalização dos direitos humanos se inicia buscando proteger tal direito na esfera internacional. Todavia, na perspectiva global dos direitos e necessidades humanas, não se limitam somente ao rol especificado na Declaração, tendo em vista, que as diferentes culturas apresentam vários contrastes filosóficos, políticos, econômicos, culturais, que não são levados em consideração por ela.

Enfim, os direitos humanos derivam do direito natural, possuem efetividade $\mathrm{e}$ maior garantia em sistemas jurídicos de países com regime democrático que prioriza a dignidade da pessoa humana, aprova tratados e convenções que versam sobre tais direitos, a fim de vincular os governantes e o sistema de administração de justiça na auto aplicabilidade.

Determinar direitos mínimos aos seres humanos é compreender que a liberdade moral existe de forma intrínseca na prática dos projetos de vida humano, vivenciados a partir da liberdade e da autoconsciência. O diálogo entre culturas, típico no multiculturalismo, é viável a partir da perspectiva relativista. Isso porque, o relativismo dá prioridade à reflexão dos direitos humanos a partir de sua práxis social. Torna-se mais fácil a delimitação dos diferentes aspectos, comuns às diversas culturas, de maneira a se desenvolver as características base do multiculturalismo.

Desse modo, o fenômeno cultural brasileiro é maior e integrante do próprio ser coletivo. Portanto, o relativismo dos direitos humanos é necessário para a proteção da identidade cultural, e reconhecer o multiculturalismo, pois a universalização nivela os valores a uma racionalidade que é a própria razão de ser dos direitos humanos. Para que os direitos humanos possam ser universais, o respeito às culturas diversas, deve ser ensinado para que cada individuo tenha a percepção de quando a cultura é benéfica representa uma ofensa ao íntimo dos cidadãos. 


\section{REFERÊNCIAS}

AGAMBEN, Giorgio. Homo sacer: o poder soberano e a vida nua. 2 ed. Trad. Henrique Burigo. Belo Horizonte: UFMG, 2002.

AMARAL, Leonardo Correa; BORANGA, Rodolfo. Direitos humanos após a segunda guerra mundial. In: Simpósio de Ciências Aplicadas da FAIT, 12., 2015, Itapeva. Anais eletrônicos... Itapeva: FAIT, 2002. Disponível em: http://www.egov.ufsc.br/portal/sites/default/files/direitos_humanos.pdf. Acesso em: 10 dez. 2018.

ANTAS JUNIOR, Ricardo Mendes. Território e regulamentação espaço geográfico, fonte material e não formal do direito. São Paulo: Saraiva, 2005.

ARENDT, Hannah. Origens do totalitarismo. Trad. Roberto Raposo. São Paulo: Companhia das Letras, 2007.

BARATTO, Marcia. Multiculturalismo e direitos humanos. Conexão Política, [S.I.], v. 3, n. 1 p. 5- 17, jan./jul. 2014.

BOBBIO, Norberto. A era dos direitos. Trad. Carlos Nelson Coutinho; apresentação de Celso Lafer. Rio de Janeiro: Elsevier, 2004.

BRASIL. Secretaria de Direitos Humanos da Presidência da República Programa Nacional de Direitos Humanos (PNDH-3). Brasília: SDH/PR, 2010. Disponível em: http://www.pndh3.sdh.gov.br/portal/sistema/sobre-o-pndh3. Acesso em: 04 abr. 2018.

BURKE, Edmund. Reflexões sobre a revolução em França. Brasília: UNB, 1982.

DONNELLY, Jack. Direitos humanos internacionais: consequências não intencionais da guerra contra o terrorismo, Contexto internacional, [S.I.], v. 25, n. 2, p. 333-361, jul./dez. 2003.

ENGELMANN, Fabiano; MADEIRA, Lígia Mori. A causa e as políticas de direitos humanos no BRASIL. Caderno CRH, Salvador, v. 28, n. 75, p. 623-637, set./dez. 2015.

KOERMER, Andrei. O papel dos direitos humanos na política democrática: uma análise preliminar. Revista brasileira de Ciências Sociais, [S.I.], v. 18, n. 53, p. 143-157, out. 2003.

MARX, Karl. A questão judaica. Trad. Daniel Bensaid e Wanda Caldeira Brant. São Paulo: Boitempo, 2010. 
MONTERO, Paula. Multiculturalismo, identidades discursivas e espaço público. Sociologia \& Antropologia, [S.I.], v. 2, n. 4, p. 81-101, jun. 2012.

MUNIZ, Anna Carolina Vasquez. Direitos humanos e política internacional. 2009. Disponível em:

http://www.pucrio.br/pibic/relatorio_resumo2010/relatorios/ccs/iri//RIAnna\%20Carolin a\%20Vasquez\%20Muniz.pdf. Acesso em: 20 abr. 2018.

OLIVEIRA, Eliane de; SOUZA, Maria Luiza de. Multiculturalismo, diversidade cultural e direito coletivo na ordem contemporânea. Cadernos da Escola de Direito e Relações Internacionais, Curitiba, v. 3, n. 16, p. 121-139, 2011.

PINHEIRO, Paulo Sergio; MESQUITA NETO, Paulo de; Programa Nacional de Direitos Humanos: avaliação do primeiro ano e perspectivas. Estudos avançados, [S.I.], v. 11, n. 30, p. 117-34, 1997.

PIOVESAN, Flavia. Ações afirmativas da perspectiva dos direitos humanos.

Cadernos de Pesquisa, [S.I.], v. 35, n. 124, p. 43-55, jan./abr. 2005.

SHACHAR, Ayelet. Multicultural jurisdictions: cultural differences and women's rights. Cambridge: Cambridge University Press, 2001.

SOUSA, Joelma Melo. A identidade nacional brasileira em discursos jurídicos: entre memória, narrativa histórica e constitucional. 2010. Dissertação (Mestrado em Direito) - Faculdade de Direito de Brasília, Brasília, 2010.

TOSI, Giuseppe; FRAGOSO, Williard Scorpion. As críticas de direita e esquerda aos direitos humanos. Revista Problemata, [S.I.], v. 8, n. 1, p. 122-62, 2017.

UNESCO. Declaração universal sobre a diversidade cultural. 2002. Disponível em:

http://unesdoc.unesco.org/images/0012/001271/127160por.pdfhttp://unesdoc.unesco .org/images/0012/001271/127160por.pdf. Acesso em: 22 mar. 2018. 